\title{
Spatial and temporal UV irradiance and aerosol variability within the area of an OMI satellite pixel
}

\author{
S. Kazadzis ${ }^{1,2,5}$, A. Bais ${ }^{2}$, D. Balis ${ }^{2}$, N. Kouremeti ${ }^{2}$, M. Zempila ${ }^{2}$, A. Arola ${ }^{3}$, E. Giannakaki ${ }^{2}$, V. Amiridis ${ }^{4}$, and \\ A. Kazantzidis ${ }^{2}$ \\ ${ }^{1}$ Finnish Meteorological Institute, Climate Change Unit, Helsinki, Finland \\ ${ }^{2}$ Laboratory of Atmospheric Physics, Aristotle University of Thessaloniki, Greece \\ ${ }^{3}$ Finnish Meteorological Institute, Kuopio Unit, Finland \\ ${ }^{4}$ National Observatory of Athens, Institute of Space Applications and remote sensing, Athens, Greece \\ ${ }^{5}$ National Observatory of Athens, Institute for Environmental Research and Sustainable Development, Athens, Greece
}

Received: 29 December 2008 - Published in Atmos. Chem. Phys. Discuss.: 19 March 2009

Revised: 04 June 2009 - Accepted: 30 June 2009 - Published: 16 July 2009

\begin{abstract}
Results of an experimental campaign that took place in the greater Thessaloniki area were used to investigate temporal and spatial UV variability within an OMI satellite pixel. UV irradiance and aerosol optical depth measurements were performed for a one month period at three sites characterized as urban, rural and industrial, depending on their location and possible local aerosol sources. OMI showed a general UV irradiance overestimation compared to all three sites and for all atmospheric conditions. During the campaign the standard deviation calculated from the three sites for UV irradiance at $324 \mathrm{~nm}$ was of the order of $26 \%$. For cloudless days with high spatial aerosol variability, UV differences reached $\pm 20 \%$ within the OMI pixel. For cloudy days UV differences up to $100 \%$ were found at the three sites, a percentage that depends on the ground-based data integration time used for the comparison. Here we tried to focus on the limitations when trying to interpret results of UV irradiance comparisons between OMI satellite and ground based stations, taking into account the UV variability within an OMI pixel, due to such small scale spatial cloud and aerosol inhomogeneities.
\end{abstract}

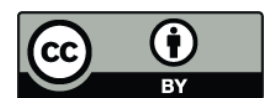

Correspondence to: S. Kazadzis (stylianos.kazantzis@fmi.fi)

\section{Introduction}

Ultraviolet (UV) irradiance increase due to the stratospheric ozone depletion has been an issue for the past three decades due to its link with human health (e.g. United Nations Environmental program, 1998; National Radiological Protection board, 2002). Ground-based (GB) measurements of surface UV irradiance have been developed in many countries and a series of instruments were devoted to UV monitoring purposes (WMO, 2007 and references therein). In addition, satellite instruments, which allow a global geographical UV coverage, have been also introduced (e.g. Krotkov et al., 2002; Tanskanen et al., 2008). Satellite UV measurements are affected by instrumental errors, similarly to GB measurements (Bernhard and Seckmeyer, 1999). In addition they are also affected by modeling uncertainties in deriving surface UV irradiance from backscattered UV measured at the top of the atmosphere (Krotkov et al., 2001; Tanskanen et al., 2006). Therefore, satellite validation becomes essential for ensuring high quality UV irradiance products.

Surface UV irradiance is provided by the Ozone Monitoring Instrument (OMI), flying on the NASA EOS AURA satellite, which may be regarded as a continuation of the measurements by the Total Ozone Monitoring System (TOMS). OMI is a spectrometer designed to monitor ozone and other atmospheric species (Levelt et al., 2006). OMI UV products consist of spectral irradiance at $305,310,324$, and $380 \mathrm{~nm}$ retrieved for the local overpass time and also calculated for local solar noon, as well as of erythemal dose rates and erythemal daily doses (Tanskanen et al., 2008).

Published by Copernicus Publications on behalf of the European Geosciences Union. 
Satellite ozone and UV data were exhaustively validated by means of GB measurements, regarding TOMS; (Kalliskota et al., 2000; McKenzie et al., 2001; Krotkov et al., 2001; Fioletov et al., 2002; Meloni et al., 2005; Arola et al., 2005; Kazantzidis et al., 2006) and lately OMI; (Tanskanen et al., 2008; Ialongo et al., 2008; Weihs et al., 2008; Kazadzis et al., 2009; Buchard et al., 2008). All these validation studies converge to the following conclusions:

- At snow-free conditions, satellite-derived spectral UV irradiance data are up to $40 \%$ higher than the GB data. In most cases the biases range between $5 \%$ and $20 \%$.

- The smallest biases have been found at unpolluted locations.

- The largest relative differences between the satellitederived and measured irradiances are observed in urban areas and have been attributed to tropospheric aerosol absorption not included in the satellite UV retrieval algorithm.

All validation results should be treated with caution because of the different geometries involved. The GB measurements are representative of only a small area, whereas satellite measurements are representative of a large region (OMI minimum pixel at nadir $13 \times 24 \mathrm{~km}^{2}$ ), thus further uncertainties may arise from the cloud or aerosol variability, parameters that both affect UV irradiance, inside the satellite pixel area. The influence of ground inhomogeneity on the UV retrieval as well as the representativeness of the derived UV at one OMI pixel is an issue that only few studies have approached (Weihs et al., 2008). In the work of Weihs et al. (2008) measurements within one OMI satellite pixel were used to investigate the inhomogeneity of UV and so to give hints concerning possible UV fluctuations. Their results for UV erythemal dose variability within one OMI satellite pixel showed deviations up to $\pm 5 \%, \pm 10 \%$ and $\pm 50 \%$ for cloudless, partly cloudy and overcast conditions, respectively.

For the area investigated here Kazadzis et al. (2009) have compared spectral ultraviolet overpass irradiances from OMI against ground-based Brewer measurements at Thessaloniki, Greece from September 2004 to December 2007. It is demonstrated that OMI overestimates UV irradiances by $30 \%, 17 \%$ and $13 \%$ for $305 \mathrm{~nm}, 324 \mathrm{~nm}$, and $380 \mathrm{~nm}$ respectively and $20 \%$ for erythemally weighted irradiance. Cloudless and cloudy conditions were investigated separately and for cloudless conditions aerosols play the most important role for such deviations. Comparing total column ozone values retrieved from OMI and GB measurements we found a small OMI ozone under-estimation in the order of $1.2 \%$ (mean). The effect of this difference in the irradiance comparison at $305 \mathrm{~nm}$ varies from $2 \%$ to $4 \%$ for the solar zenith angle range of OMI overpasses and it is negligible for the irradiance comparisons at higher wavelengths.
In this work we present the results of a campaign aiming to measure spectral UV and aerosol optical properties within one OMI pixel, and to discuss possible OMI and GB spatial and temporal related differences. We have tried to focus on the following aspects:

- Linking of possible OMI overestimation of UV irradiances levels with the findings of a three and half year OMI UV validation study (Kazadzis et al., 2009) at the urban area of Thessaloniki, Greece.

- Quantification of the effect of aerosol variability within an OMI pixel which contains areas that are characterized according to the aerosol sources as: urban, industrial and rural.

- Reveal the influence of surface effects on GB and OMI UV comparison and investigate temporal characteristics of UV irradiances measured at three points with different characteristics in terms of aerosol loading, within the OMI pixel.

\section{Location and instrumentation}

In order to investigate the spatial and temporal differences between the OMI UV products and GB measurements, an experimental campaign was held from 1 to 30 October 2007 at Thessaloniki, Greece $\left(40.6^{\circ} \mathrm{N}, 22.9^{\circ} \mathrm{E}\right)$, a city with a population of approximately 1.2 million. The site is facing the Aegean Sea to the south and west and is situated along expected pathways through which pollution from central and Eastern Europe influences aerosol loading over the Eastern Mediterranean (Amiridis et al., 2005; Koukouli et al., 2006). Aerosol optical depth (AOD) measurement records (Kazadzis et al., 2007) show that AOD values at Thessaloniki area are among the highest at European level.

The OMI surface UV algorithm is an extension of the TOMS UV algorithm developed at NASA Goddard Space Flight Center (GSFC) (Krotkov et al., 1998; Herman et al., 1999; Krotkov et al., 2001; Tanskanen et al., 2006). The OMI surface UV algorithm is used for offline production of the global surface UV data using as input the OMI TOMS total column ozone (Bhartia and Wellemeyer, 2002) and reflectance at non-absorbing wavelength $(360 \mathrm{~nm})$. A more detailed summary of the OMI-UV retrieval can be found in Kazadzis et al. (2009).

UV irradiance and aerosol optical properties were measured at three different locations in the greater area of Thessaloniki, representing different air quality conditions:

- An urban area (UA) site situated at the city center, at the Aristotle University of Thessaloniki (AUTH).

- A rural area (RA) site situated outside a small village (Epanomi) situated $26 \mathrm{~km}$ to the south of the city center and well outside the city limits. 
- An industrial area (IA) site situated inside the industrial zone of Thessaloniki (Sindos - EIM), Situated $12 \mathrm{~km}$ at the west of the urban site.

A map of the area, including the three sites is shown in the following Fig. 1.

For this experimental campaign the participating institutes were: The Aristotle University of Thessaloniki, the NASA/Goddard Space Flight Center, the National Observatory of Athens and Raymetrics, S. A. Inc. The campaign was supported by a series of different instruments measuring a suite of UV radiation and aerosol related parameters. More specifically, the following measurements were conducted:

- Spectral measurements of direct and global UV irradiance at the surface performed by two Brewer spectroradiometers at the UA site (instrument and measurement details in Garane et al., 2006; Kazadzis et al., 2005). In addition, global irradiance at $305 \mathrm{~nm}, 310 \mathrm{~nm}$ and $380 \mathrm{~nm}$ (OMI wavelengths) were measured on a minute basis, at each of the three sites with three NILU-UV multi-channel radiometers that are part of the Greek UV Network (www.uvnet.gr). In additions, NILU measurements at $320 \mathrm{~nm}$ were converted to UV irradiance at $324 \mathrm{~nm}$ using simple polynomial functions derived from the combination of the NILU and Brewer spectroradiometer. All NILU-UV instruments were compared and calibrated before the start, and checked after the end of the campaign with the help of calibration lamps and synchronous measurements with the Brewer spectroradiometer, in order to maintain comparability of their measurements during the campaign.

- AOD measurements at $340 \mathrm{~nm}$ with two CIMEL automatic sun tracking photometers, installed at RA and IA sites. AOD at $340 \mathrm{~nm}$ was also retrieved from the Brewer direct spectral irradiance measurements at the UA site (Bais, 1997).

- In-situ measurements of aerosol vertical profiles were derived from two LIDAR systems operating at UA and RA sites (instrument and measurement details in Amiridis et al., 2005).

- Total ozone column was derived from a Brewer single monochromator and cloud observations and sky images at the UA site. Cloud observations were performed at all sites on a half hour basis, and in addition sky images were taken every $15 \mathrm{~min}$ at the UA site.

One of the approaches tested was to compare UV irradiances derived from OMI with those measured at the three sites, as well as with their average, in order to test whether the main UA site is representative for the greater OMI pixel area, and whether the comparison with OMI is improved when data from stations in the vicinity are averaged.

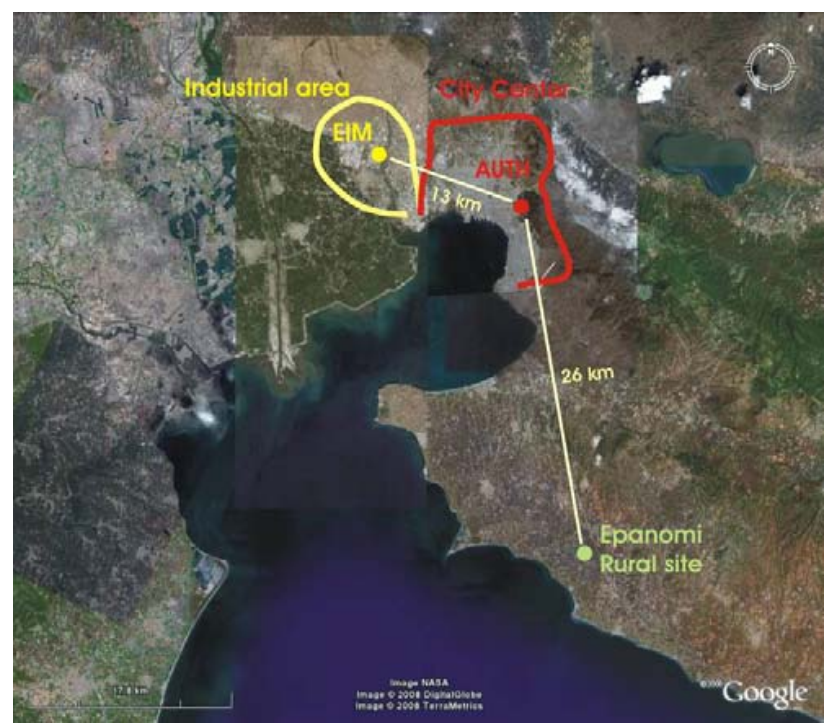

Fig. 1. Map of greater Thessaloniki area. UA (red dot), IA (yellow dot) and RA (green dot) sites are shown. City and industrial area limits are shown with red and yellow lines respectively (Courtesy of Google Earth NASA Images).

\section{Results and discussion}

\subsection{Spectral UV irradiance measurements}

Surface UV irradiance measurements with the NILU-UV multi-filter radiometers for the three sites and with the Brewer spectroradiometer at the UA site were compared with the OMI UV products. The data for both instruments correspond to the average of all measurements within a time window of \pm 15 min around the OMI overpass time. The spectral irradiance measured at $324 \mathrm{~nm}$ during the campaign is shown in Fig. 2.

The campaign data series include a mix of cloudless, partly cloudy and a few overcast cases. According to the work of Kazadzis et al. (2009), OMI exhibits a wavelength dependent overestimation of the irradiance at the surface by up to $30 \%, 17 \%$ and $11 \%$ respectively for $305 \mathrm{~nm}, 324 \mathrm{~nm}$ and $380 \mathrm{~nm}$ for all atmospheric conditions.

Mean irradiance differences at $324 \mathrm{~nm}$ between OMI and the ground based instruments at the three campaign sites are shown in Table 1.

The results of Fig. 2 and Table 1 show that the main problem when comparing OMI and GB measurements for urban areas is the OMI UV overestimation as described in detail in Tanskanen et al. (2008), Kazadzis et al. (2009) and Ialongo et al. (2008). When averaging OMI and GB measurements for each site and for the whole campaign period the OMI overestimation is similar to the one reported by Kazadzis et al. (2009) from a three and a half years period of observations at $324 \mathrm{~nm}$. Results of this campaign period have been showed more overestimation for the irradiance at $305 \mathrm{~nm}$ and 


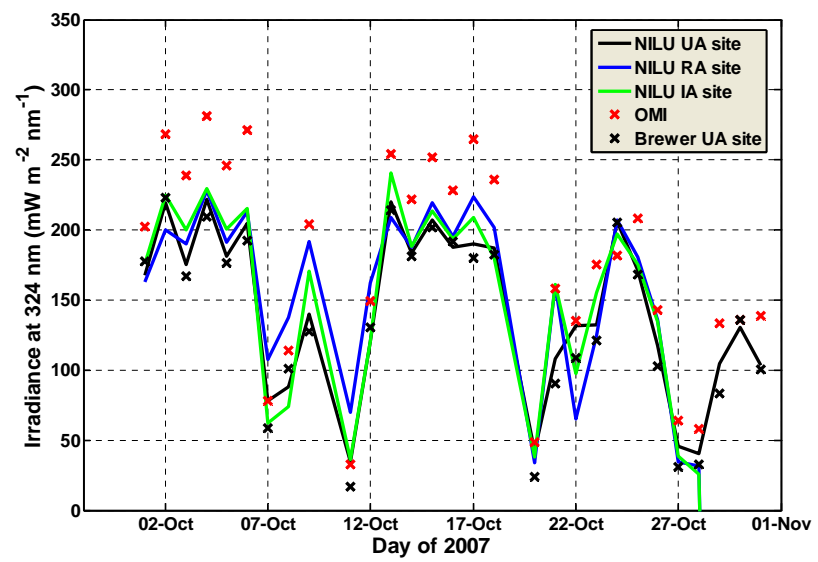

Fig. 2. Variability of spectral irradiance at $324 \mathrm{~nm}$ for October 2007 at the three campaign sites as derived from OMI, Brewer and NILU$\mathrm{UV}$. The data for all GB instruments correspond to the average of all measurements within a time window of $\pm 15 \mathrm{~min}$ around the OMI overpass time.

Table 1. Differences in irradiance at $324 \mathrm{~nm}$ between OMI and GB instruments.

\begin{tabular}{lcc}
\hline Difference of OMI from & Mean bias $(\%)$ & Standard deviation $(1 \sigma)$ \\
\hline UA site & +15 & 16 \\
RA site & +18 & 50 \\
IA site & +21 & 31 \\
Average of the three & +16 & 26 \\
2004-2007 average & +17 & 16 \\
\hline
\end{tabular}

less overestimation for $380 \mathrm{~nm}$ in agreement with the results in Kazadzis et al. (2009). The day to day UV variability is large as evidenced by the standard deviation shown in Table 1 . Most of this variability is due to the presence of clouds in one or more sites. In Fig. 3, the irradiance at $380 \mathrm{~nm}$ measured at each site for all days of the campaign at the time of the OMI overpass ( $\pm 15 \mathrm{~min})$ is compared with the corresponding OMI products.

From Fig. 3 it appears that at this wavelength there is smaller deviation between the ground based irradiance measurements at all sites and the OMI derived irradiance at $380 \mathrm{~nm}$ than the one detected at $324 \mathrm{~nm}$ (Fig. 2, Table 1). Under cloudy conditions, there is a general OMI UV overestimation. When comparing instantaneous measurements of the NILU-UV instruments (measurements at the exact minute of OMI overpass) with OMI, occasionally and under variable cloudiness, OMI reported irradiance values twice as high, at least in one of the three sites. These cases are associated also with differences in the timing the sun was visible, during the $30 \mathrm{~min}$ of the averaged ground based measurements. Under such conditions, the comparison is meaningless, as the two instruments (ground based and satellite) sense the radiation

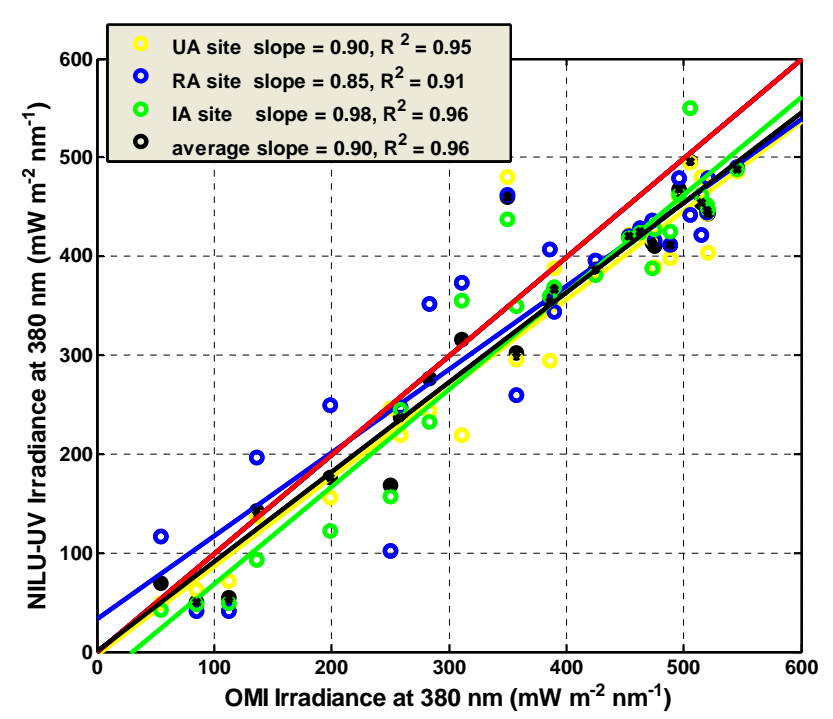

Fig. 3. Comparison of spectral irradiance at $380 \mathrm{~nm}$ measured by three NILU-UV radiometers at UA (yellow), RA (blue) and IA (green) with the OMI derived irradiance at the same wavelength. The black symbols correspond to the average of the three sites. The lines are linear fits on the data and the red line represents the $Y=X$ function. The data for NILU instruments correspond to the average of all measurements within a time window of $\pm 15 \mathrm{~min}$ around the OMI overpass time.

field from a totally different spatial approach. It is worth to mention that rarely the OMI UV products are lower than the GB measurements. This mainly occurs when there are few clouds in the OMI grid, so that the OMI cloud correction is very small, while the direct sun irradiance is obscured by a small cloud and is not measured by the instrument at the ground.

\subsection{Aerosol Optical Depth variability}

During the campaign, AOD measurements at $340 \mathrm{~nm}$ were performed by 2 CIMEL sun photometers and a Brewer spectroradiometer when the solar disk was free of clouds. The variability of AOD during the campaign was high (Fig. 4). There were days with AOD higher than 1, periods of atmospheric aerosol loading building up at all three sites, a period with Saharan dust intrusion (6-9 October), days with notable AOD differences between the three sites (16-18 October) and finally days with extremely low (for the specific area) AOD (22 October). In order to have a reference for comparison, the mean AOD at $340 \mathrm{~nm}$ over Thessaloniki during the last decade is 0.35 for wintertime, 0.55 for summertime and 0.48 for October (Kazadzis et al., 2007).

Taking into account only quasi synchronous measurements (maximum difference of $10 \mathrm{~min}$ ), the average AOD differences of the rural and the industrial sites from the UA site during the period of the campaign were found 


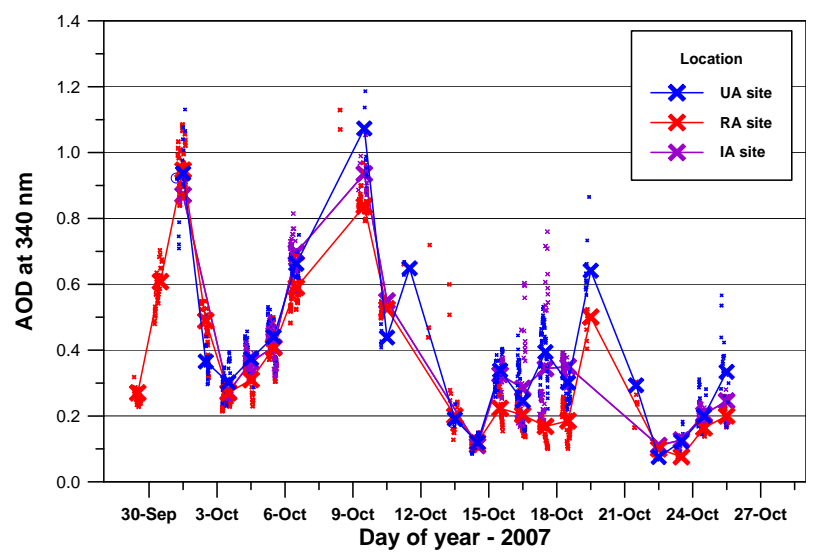

Fig. 4. Aerosol optical depth at $340 \mathrm{~nm}$ measured with two CIMEL sun photometers and a Brewer spectroradiometer at the three campaign sites. Large symbols represent daily averages while the smaller symbols correspond to the individual measurements.

respectively -0.07 and 0.01 . However, there were cases with AOD differences of up to 0.45 (corresponding to a relative difference of $100 \%$ ). Despite the different characteristics of the three sites with respect to the prevailing aerosol sources, in most cases the AOD seems to follow similar patterns. Especially on 9 October (Saharan dust intrusion event) the AOD was high at all three stations and this was confirmed also from the LIDAR measurements.

The difference in AOD between the UA and the RA sites for specific days are mainly attributed to differences in the aerosol loading inside the boundary layer. To confirm this assumption we have compared the aerosol backscattering profiles at $532 \mathrm{~nm}$ derived at the UA site with the AUTH Raman - backscatter LIDAR and at the rural site with the RAYMETRICS backscatter LIDAR, shown in Fig. 5. For 16 October 2007, one can observe the backscatter profiles for the two sites showing almost the same contribution in the free troposphere. The optical depth for that day was $0.24 \pm 0.08$ for the UA and $0.19 \pm 0.05$ for the RA site. The difference of about 0.05 in the aerosol optical depth lies within the uncertainty of the measurements. On the other hand, for the 18 October 2007, while the backscatter profiles are very similar in the free tropospheric, the contribution of the aerosols in the boundary layer is different between the two sites. The AOD for that day was $0.3 \pm 0.05$ for the UA and $0.18 \pm 0.05$ for the RA and this difference can mainly be attributed to the contribution of local aerosol sources in the boundary layer of the city of Thessaloniki.

A closer look at individual days reveals marked AOD differences among the three sites. The UV measurements at $380 \mathrm{~nm}$ at the three sites showed that such differences can cause deviations of up to $20 \%$ when comparing synchronous cloudless sky measurements at the three sites, as shown in Fig. 6. Patterns like the AOD increase at IA site in the

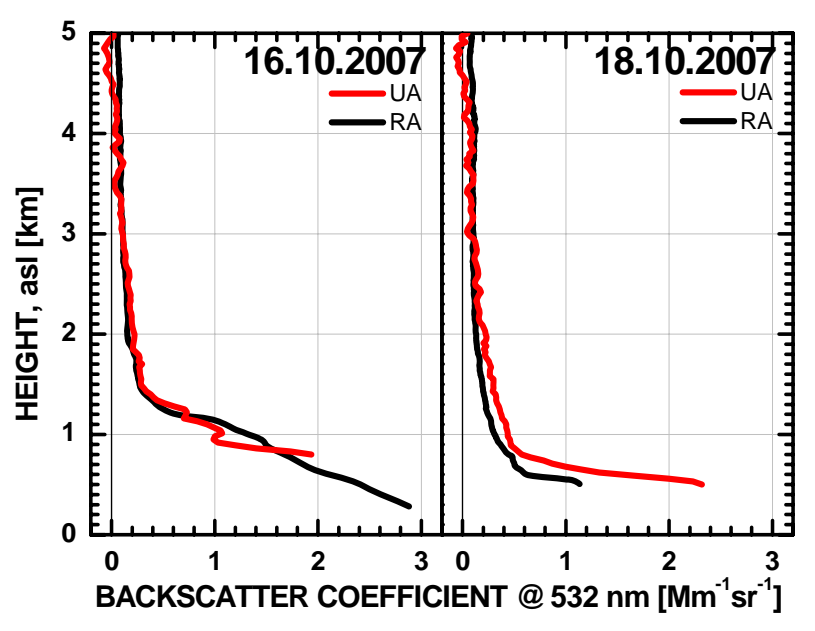

Fig. 5. Daily averaged profiles of the backscatter coefficient at $532 \mathrm{~nm}$ derived from LIDAR measurements at the UA site (Thessaloniki) and the RA site (Epanomi) on the 16th (left) and 18th (right) of October 2007.

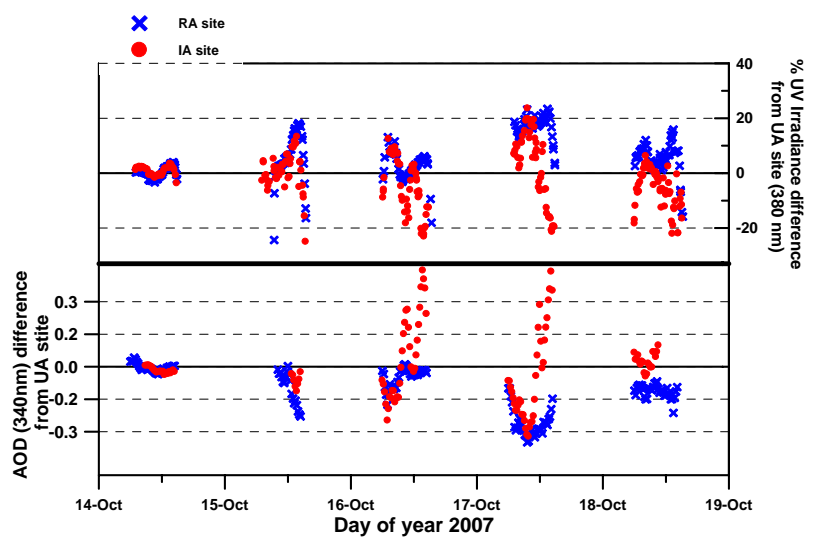

Fig. 6. Relative differences of AOD (lower panel) and spectral irradiance at $380 \mathrm{~nm}$ (upper panel) between IA (red) and RA (blue) sites from the UA site during 5 consecutive cloud free days.

afternoon of 16 and 17 October lead to differences up to $20 \%$ in the irradiance measured at the two stations. The diurnal pattern at the UA site on 17 October that is not found at RA and IA sites leads to similar negative UV deviations. On 14 October, when the AOD at all stations was constant, in the order of 0.1 , the UV irradiance measurements from the three NILU-UV instruments deviated only by up to $\pm 3 \%$, which is within the instrumental uncertainty. The differences in AOD between the three sites, distributed within an OMI pixel, result into marked differences in the measured surface irradiance. However, when comparing measurements from the ground with satellite overpasses the same satellite estimate applies for all three sites. This suggests that local variability factors (such as aerosols) that are capable in modifying surface UV irradiance cannot be detected in the measurements 


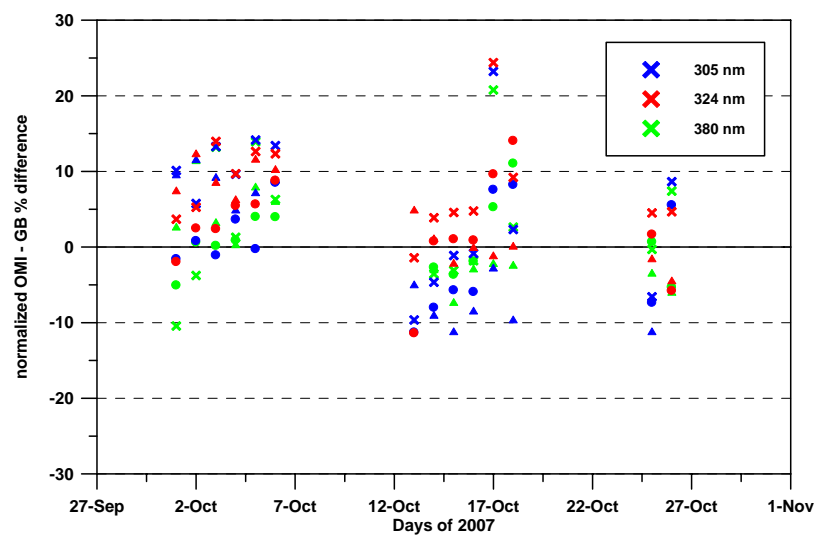

Fig. 7. Relative difference between OMI derived and ground based irradiance, normalized with the long term absolute difference, measured at the OMI overpass time during cloud free days at all three sites (UA crosses, RA triangles and IA circles) and for the wavelengths shown. The ground based data are averages within $\pm 30 \mathrm{~min}$ from the OMI overpass time.

of a single ground station, while they are taken into account in the satellite estimates since they affect the average radiance measured by the satellite. Therefore comparisons of satellite overpass data with single ground stations may suffer from such local variability of aerosols. Such effects may result in overestimation of the satellite irradiance, when the measuring site at the surface is located in an urban area surrounded by a rural area within a sub satellite pixel, or vice versa.

\subsection{Comparisons with OMI overpass data}

Similar results with those discussed above are observed when analyzing data corresponding only to OMI overpasses. Figure 7 shows relative differences between OMI derived and ground based irradiance measurements during the campaign period, normalized with the long term absolute differences that were found for the specific area by Kazadzis et al. (2009). The normalization was applied in order to isolate the spatial variability within the OMI pixel, independent of the absolute and spectral differences in irradiance.

As can be seen in Fig. 7, deviations in the first period (16 October) are somewhat higher compared to the rest, associated with the higher AOD (see Fig. 4). The gradual increasing deviations are due to the continuous buildup of the aerosols. For the second period (12-17 October) lower AOD led to smaller differences. This is because the OMI UV irradiance retrieval is practically unaffected by aerosols with optical depths of the order of 0.1 (as e.g. in 14 October). As it has been repeatedly reported, the main problem in the OMI UV retrieval is the presence of absorbing aerosols in the lower troposphere (e.g. Arola et al., 2005). Aerosols in the boundary layer do not buildup in a spatially homogeneous

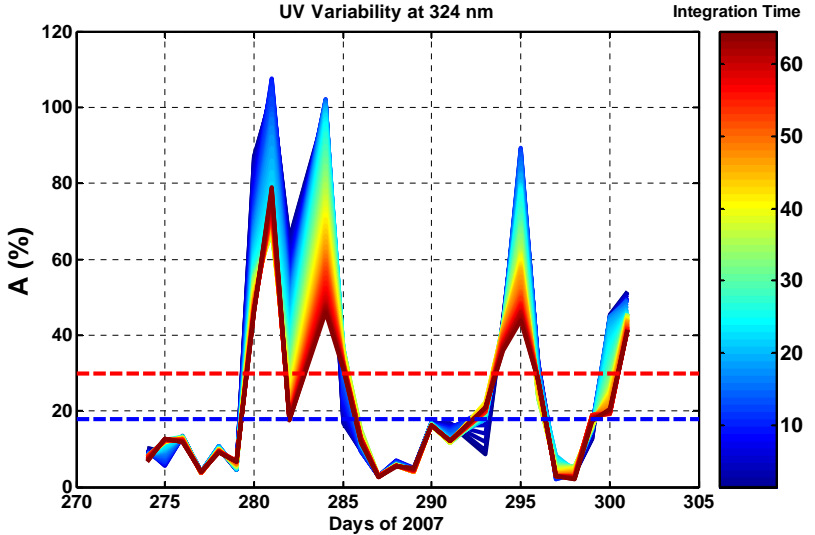

Fig. 8. Day-to-day variability of the parameter $A$ calculated from irradiance measurements at $324 \mathrm{~nm}$ at all the three sites during the campaign period. Different colours correspond to different averaging intervals of irradiance around the OMI overpass time. The blue (red) dashed line is a limit enclosing $90 \%$ (80\%) of the relative differences between OMI and GB measurements from 3.5 years of data under cloudless skies.

manner, causing large differences when comparing OMI and GB measurements among the three locations, as it happens after the 14th of October. Especially for 16 and 17 October, even hourly averages of GB irradiance measurements differ by up to $20 \%$ among the three sites. The results presented in this figure demonstrate the limitations on interpreting the statistics, and particularly the standard deviations, when comparing GB and OMI UV measurements.

For a more detailed-statistical interpretation of the spatial and temporal UV variability within the satellite grid we used the parameter $A$ denoting the interval from the mean UV irradiance at a specific wavelength, that $95 \%$ of the total number of measurements lie within. This parameter was used as a measure of the variability of the irradiance at the three stations within the sub-satellite pixel area:

$A(\lambda, t)=[2 * \sigma(\lambda, t) / \bar{I}(\lambda, t)] * 100$

where $\bar{I}$ and $\sigma$ are the mean and the standard deviation of UV irradiance at wavelength $\lambda$, calculated for each day from the UV measurements at the three stations averaged over $t$ minutes centred at the OMI overpass time.

The blue line in Fig. 8 corresponds to the lowest averaging interval ( $\pm 1 \mathrm{~min}$ from the OMI overpass time), and the red line to the largest $( \pm 30 \mathrm{~min})$. On cloudy days, the parameter $A$ is higher than $40 \%$ exceeding $100 \%$ in two cases with the highest cloud-induced variability in irradiance over the area. As seen in Fig. 8, the fluctuations of the measured UV irradiances for cloudy conditions are larger. This can be explained mainly through differences in cloud cover and cloud reflection at the different measurement sites at the same time. For the specific campaign the number of days with variable or overcast cloud conditions was limited. Similar 
work of Weihs et al. (2008) showed under partly cloudy conditions the satellite UV-values are, on average, in the order of $30 \%$ higher than the ground observations. The ratio OMI to ground UV becomes even larger for overcast conditions. The satellite overestimates the observed ground values by more than $50 \%$. However, it is difficult to determine partly or overcast conditions for a number of stations since having overcast conditions in one location and broken cloud conditions in another, is the case that causes the larger uncertainties even when integrating irradiance measurements for large time intervals.

For cloudless cases, the parameter $A$ becomes larger (up to $\sim 18 \%$ ) when large deviations of AOD were observed (days 290 and 291). It should be noted that the comparison of 3.5 years of OMI and Brewer measurements (Kazadzis et al., 2009) showed that $90 \%$ of the cloudless days lie within $\pm 18 \%$ from the mean difference. The observed variability during the campaign suggests that it is difficult to find agreement between OMI and GB irradiance on a level of a few per cent, even for cloudless cases, due to the spatial variability of UV irradiance inside the OMI pixel. This holds unless there is a proof that within the sub-satellite pixel there are no major differences of the columnar AOD and aerosol absorption properties. These conditions rarely occur inside pixels containing urban areas.

The comparison of the average UV irradiance from the three stations with OMI at all wavelengths (here shown only for $324 \mathrm{~nm}$ ) is improved especially on cloudy days when using larger averaging intervals. The average UV variability for the whole period, (expressed again with the $A$ parameter) for different averaging intervals can be also seen in Fig. 9. Here $A(\lambda, \mathrm{t})$ represents the mean $A(\lambda=324, \mathrm{t})$ averaged for all 30 days of the campaign for different averaging times $t$, centred at the OMI overpass time.

Figure 9 suggests that comparing OMI with GB measurements averaged for up to $10 \mathrm{~min}$, the parameter $A$ is rather constant ranging between $29 \%$ and $30 \%$. For 60 min averaging (i.e. within $30 \mathrm{~min}$ from OMI overpass time) $A$ drops to $20.7 \%$. Weather conditions and the length of the measurements period play an important in the statistics. Similar analysis in the summertime (with only a few cloudy days, thus fewer possibilities for high UV variability inside the OMI pixel) would lead to lower $A$ values. On the contrary, in areas with more clouds the UV variability is higher (higher $A$ values). The month of October 2007, for the area of Thessaloniki, was a well mixed period, in terms of weather conditions, including cloudless and cloudy days, but also days with different aerosol load.

\section{Conclusions}

The experimental campaign that took place in the Thessaloniki greater area in October 2007 showed high day to day UV variability mostly due to clouds, whereas for cloudless

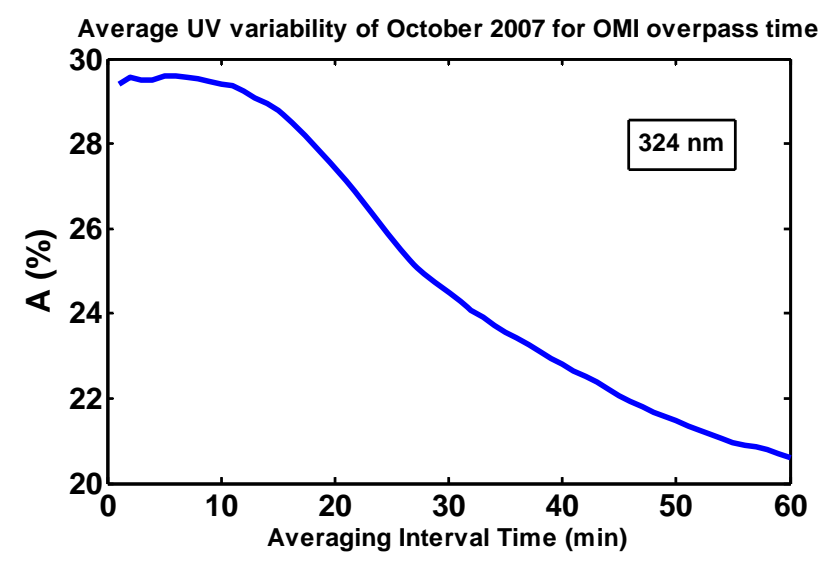

Fig. 9. Average surface irradiance variability at $324 \mathrm{~nm}$ from all three sites and for the entire campaign period for different averaging intervals.

days the variability is attributed to spatial variations in the aerosol optical depth in the $13 \times 25 \mathrm{~km}$ grid of the campaign sites which is similar in size to the OMI sub-satellite pixel.

For days with cloudy conditions, large UV irradiance differences of up to $100 \%$ were found among the three sites, depending on the averaging interval used in GB measurements. Especially for partly cloudy cases, the presence of clouds in the path between the sun and the GB instruments can cause major difficulties in quantifying the differences between the OMI and GB measurements. Longer averaging intervals for the GB measurements can improve the statistics of the comparison. Especially under cloudy conditions, UV instruments with high frequency measurements (e.g. multi-filter radiometers or broadband detectors) provide more important information than scanning spectroradiometers for satellite validation. Because of the importance of clouds in modifying the UV irradiance at the surface, weather patterns favoring the generation of local clouds should to be taken into account for choosing the location of a GB station used for satellite validation.

The three GB sites, where UV irradiance and AOD measurements were performed, are characterized by different aerosol sources (urban, industrial and rural). At some cloudless cases it was found that spatial aerosol optical depth differences among the three sites can cause differences of up to $20 \%$ in UV irradiance. This shows the limitation of the OMI UV validation due to such small scale spatial aerosol variability, even without the presence of clouds. For such cases the location of a single station that could be used for satellite validation would randomly affect any OMI UV validation attempt aiming to better accuracy.

Comparison of 3.5 years of GB spectral measurements with OMI UV spectral products (Kazadzis et al., 2009) showed that $87 \%$ to $92 \%$ (depending on wavelength) of all cloudless cases lie within $\pm 20 \%$ from the mean long term 
difference. During the campaign, the variability (standard deviation) calculated from the $324 \mathrm{~nm}$ irradiance measurements at the three sites were of the order of $26 \%$. On cloudless days with high spatial aerosol variability the $2 \sigma$ irradiance variability was $\sim 18 \%$ of the mean irradiance from the three stations. This indicates that for such cases a single point can not be considered as representative for GB and satellite comparisons. Urban areas like the one examined in this work could have similar cloud and aerosol inhomogeneity within a $13 \times 25 \mathrm{~km}$ (or larger) grid. The differences in AOD between the sites for specific days within the campaign are mainly attributed to the different aerosol load inside the boundary layer. Such differences limit any satellite validation approach independently of any algorithm or measurement improvement. In general, the average UV variability for cloudless cases was within $\pm 10 \%(1 \sigma)$ setting a lowest limit for the interpretation of differences between OMI and GB measurements.

In addition to the AOD differences among the three sites, differences in aerosol absorption properties can enhance or diminish UV variability within the OMI pixel. In this case, however, single scattering albedo measurements at the three sites showed maximum daily average differences of 0.02 , which is within the measurement uncertainty, especially when the AOD is low.

Future studies related with OMI UV algorithm improvements should include information about spatial characteristics of clouds and aerosols in the area of an OMI pixel. These characteristics should be quantified and reported in the validation results in addition to possible GB instrument or/and satellite algorithm absolute level deviations. This is because even if the interdependence of UV GB and OMI biases with factors such as clouds and aerosol optical properties would be fully explained and taken into account in a future OMI-UV post correction algorithm, the OMI and GB UV measurement agreement will be still limited by the sub-pixel spatial and temporal variability of such factors.

Acknowledgements. S. Kazadzis would like to acknowledge the Marie Curie Intra European fellowship "Validation of Aerosol optical Properties and surface Irradiance measured from Ozone Monitoring Instrument on board of AURA satellite" VAP-OMI, AOR A/119693 - PIEF-GA-2008-219908. The Dutch-Finnish built OMI instrument is part of the NASA EOS Aura satellite payload. The OMI project is managed by NIVR and KNMI in the Netherlands. We thank the OMI International Science Team for the satellite data used in this study. We would like to acknowledge the general Secretariat of Research and Technology of Greece project "Variability of UV radiation $\iota$ a complex aerosol environment derived from space and ground based observations" that was financed on the frame of the scientific and technological cooperation between organizations in Greece and in USA (project 05NONEU-469) Finally, we would like to thank the AERONET science team for the provision of one of the CIMEL instruments and for analyzing the CIMEL campaign measurements.

Edited by: A. Hofzumahaus

\section{References}

Amiridis, V., Balis, D. S., Kazadzis, S., Bais, A., Giannakaki, E., Papayannis, A., and Zerefos, C.: Four-year aerosol observations with a Raman LIDAR at Thessaloniki, Greece, in the framework of European aerosol Research LIDAR Network (EARLINET), J. Geophys. Res., 110(D21), D21203, doi:10.1029/2005JD006190, 2005.

Arola, A., Kazadzis, S., Krotkov, N., Bais, A., Groebner, J., and Herman, J. R.: Assessment of TOMS UV bias due to absorbing aerosols, J. Geophys. Res., 110, D23211, doi:10.1029/2005JD005913, 2005.

Bais A. F.: "Absolute spectral measurements of direct solar ultraviolet irradiance with a Brewer spectrophotometer", Appl. Optics, 36, 5199-5204, 1997.

Bais, A. F., Kazantzidis, A., Kazadzis, S., Balis, D. S. , Zerefos, C. S., and Meleti, C.: Deriving an effective aerosol single scattering albedo from spectral surface UV irradiance measurements, Atmos. Environ., 39(6), 1093-1102, 2005.

Balis D., Amiridis, V., Zerefos, C., and Papayannis, A.: Verification of the Experimental Determination of the LIDAR Overlap Profile by a Raman LIDAR, International Laser Radar Conference (ILRC21), Quebec, Canada, 2002.

Bernhard, G. and Seckmeyer, G.: Uncertainty of measurements of spectral solar UV irradiance, J. Geophys. Res., 104, 1432114345, 1999.

Bhartia, P. K. and Wellemeyer, C. W.: TOMS-V8 total $\mathrm{O}_{3}$ algorithm, in OMI Algorithm Theoretical Basis Document, NASA Goddard Space Flight Cent., Greenbelt, Md., 2002.

Buchard, V., Brogniez, C., Auriol, F., Bonnel, B., Lenoble, J., Tanskanen, A., Bojkov, B., and Veefkind, P.: Comparison of OMI ozone and UV irradiance data with ground-based measurements at two French sites, Atmos. Chem. Phys., 8, 4517-4528, 2008, http://www.atmos-chem-phys.net/8/4517/2008/.

Fioletov, V. E., Kerr, J. B., Wardle, D. I., Krotkov, N., and Herman, J. R.: Comparison of Brewer ultraviolet irradiance measurements with total ozone mapping spectrometer satellite retrievals, Opt. Eng., 41(12), 3051-3061, 2002.

Garane, K., Bais, A. F., Kazadzis, S., Kazantzidis, A., and Meleti, C.: Monitoring of UV spectral irradiance at Thessaloniki (19902005): Data re-evaluation and quality control, Ann. Geophys., 24(12), 3215-3228, 2006.

Herman, J. R., Krotkov, N., Celarier, E., Larko, D., and Labow, G.: Distribution of UV radiation at the Earth's surface from TOMSmeasured UV-backscattered radiances, J. Geophys. Res.-Atmos., 104(D10), 12059-12076, 1999.

Ialongo, I., Casale, G. R., and Siani, A. M.: Comparison of total ozone and erythemal UV data from OMI with ground-based measurements at Rome station, Atmos. Chem. Phys., 8, 32833289, 2008, http://www.atmos-chem-phys.net/8/3283/2008/.

Kalliskota, S., Kaurola, J., Taalas, P., Herman, J. R., Celarier, E., and Krotkov, N.: Comparison of the daily UV doses estimated from Nimbus7/TOMS measurements and ground-based spectroradiometric data, J. Geophys. Res., 105, 5059-5067, doi:10.1029/1999JD900926, 2000.

Kazadzis, S., Bais, A., Amiridis, V., Balis, D., Meleti, C., Kouremeti, N., Zerefos, C. S., Rapsomanikis, S., Petrakakis, M., Kelesis, A., Tzoumaka, P., and Kelektsoglou, K.: Nine years of UV aerosol optical depth measurements at Thessaloniki, Greece, 
Atmos. Chem. Phys., 7, 2091-2101, 2007, http://www.atmos-chem-phys.net/7/2091/2007/.

Kazadzis, S., Bais, A., Arola, A., Krotkov, N., Kouremeti, N., and Meleti, C.: Ozone Monitoring Instrument spectral UV irradiance products: comparison with ground based measurements at an urban environment, Atmos. Chem. Phys., 9, 585-594, 2009, http://www.atmos-chem-phys.net/9/585/2009/.

Kazantzidis, A., Bais, A. F., Grobner, J., Herman, J. R., Kazadzis, S., Krotkov, N., Kyro, E., den Outer, P. N., Garane, K., G“' orts, P., Lakkala, K., Meleti, C., Slaper, H., Tax, R. B., Turunen, T., and Zerefos, C. S.: Comparison of satellite-derived UV irradiances with 30 ground-based measurements at four European stations, J. Geophys. Res., 111, D13207, doi:10.1029/2005JD006672, 2006.

Koukouli, M. E., Balis, D. S., Amiridis, V., Kazadzis, S., Bais, A., Nickovic, S., and Torres, O.: Aerosol variability over Thessaloniki using ground based remote sensing observations and the TOMS aerosol index, Atmos. Environ., 40, 5367-5378, 2006.

Krotkov, N. A., Bhartia, P. K., Herman, J. R., Fioletov, V., and Kerr, J.: Satellite estimation of spectral surface UV irradiance in the presence of tropospheric aerosols 1, Cloud-free case, J. Geophys. Res.-Atmos., 103(D8), 8779-8793, 1998.

Krotkov, N. A., Bhartia, P. K, Herman, J. R., Ahmad, Z., and Fioletov, V.: Satellite estimation 5 of spectral surface UV irradiance 2: Effect of horizontally homogeneous clouds and snow, J. Geophys. Res., 106, 11743-11759, doi:10.1029/2000JD900721, 2001.

Krotkov, N. A., Herman, J. R., Bhartia, P. K., Seftor, C., Arola, A., Kaurola, J., Kalliskota, S., Taalas, P., and Geogdzhaev, I. V.: Version 2 total ozone mapping spectrometer ultraviolet algorithm: problems and enhancements, Opt. Eng., 41(12), 30283039, 2002.

Levelt, P. F., Hilsenrath, E., Leppelmeier, G. W., Van Den Oord, G. H. J., Bhartia, P. K., Tamminen, J., De Haan, J. F., and Veefkind, J. P.: Science objectives of the ozone monitoring instrument, IEEE T. Geosci. Remote, 44(5), 1199-1207, 2006.
McKenzie, R. L., Seckmeyer, G., Bais, A. F., Kerr, J. B., and Madronich, S.: Satellite retrievals of erythemal UV dose compared with ground-based measurements at northern and southern midlatitudes, J. Geophys. Res., 106, 24051-24062, doi:10.1029/2001JD000545, 2001b.

Meloni, D., di Sarra, A., Herman, J. R., Monteleone, F., and Piacentino, S.: Comparison of ground-based and Total Ozone Mapping Spectrometer erythemal UV doses at the island of Lampedusa in the period 1998-2003: Role of tropospheric aerosols, J. Geophys. Res., 110, D01202, doi:10.1029/2004JD005283, 2005.

Report of the Advisory Group on Non-ionising Radiation (AGNIR): Effects of Ultraviolet Radiation on Human Health, Documents of the NRPB, 13, No. 1, 3-276, 2002.

Tanskanen, A., Krotkov, N. A., Herman, J. R., and Arola, A.: Surface ultraviolet irradiance from OMI, IEEE T. Geosci. Remote, 44(5), 1267-1271, 2006.

Tanskanen, A., Lindfors, A., Matt, A., Krotkov, N., Herman, J., Kaurola, J., Koskela, T., Lakkala, K., Fioletov, V., Bernhard, G., McKenzie, R., Kondo, Y., O’Neill, M., Slaper, H., DenOuter, P., Bais, A. F., and Tamminen, J.: Validation of daily erythemal doses from ozone Monitoring Instrument with groundbased UV measurement data, J. Geophys. Res., 5(112), D24S44, doi:10.1029/2007JD008830, 2008.

United Nations Environment Program (UNEP): Environmental effects of ozone depletion: 1998 assessment, Nairobi, Kenya, 1998.

Weihs, P., Blumthaler, M., Rieder, H. E., Kreuter, A., Simic, S., Laube, W., Schmalwieser, A. W., Wagner, J. E., and Tanskanen, A.: Measurements of UV irradiance within the area of one satellite pixel, Atmos. Chem. Phys., 8, 5615-5626, 2008, http://www.atmos-chem-phys.net/8/5615/2008/.

World Meteorological Organization (WMO), Scientific Assessment of Ozone Depletion: Global Ozone Research and Monitoring Project, 2006, Report No. 50, World Meteorological Organization, Geneva, 2007. 